\title{
Brachioradialis Muscle
}

National Cancer Institute

\section{Source}

National Cancer Institute. Brachioradialis Muscle. NCI Thesaurus. Code C150849.

A muscle that originates from the proximal two-thirds of the lateral supracondylar ridge of the humerus and inserts into the styloid process of the radius; it enables flexion of the elbow and assists with pronation and supination of the forearm. 